\title{
Persistent hyperplastic primary vitreous - The martini glass sign
}

\author{
Author: \\ A. Fourie Bezuidenhout ${ }^{1}$

\section{Affiliation:} \\ ${ }^{1}$ Department of \\ Radiodiagnosis, Stellenbosch \\ University, South Africa
}

Correspondence to:

Fourie Bezuidenhout

Email:

fouriebez@yahoo.com

Postal address:

PO Box 19179, Tygerberg

7505, South Africa

Dates:

Received: 07 Jan. 2014

Accepted: 16 Feb. 2014

Published: 20 June 2014

How to cite this article: Bezuidenhout AF. Persistent hyperplastic primary vitreous - The martini glass sign. S Afr J Rad. 2014;18(1); Art. \#597, 1 page. http://dx.doi. org/10.4102/sajr.v18i1.597

\section{Copyright:}

(C) 2014. The Authors. Licensee: AOSIS

OpenJournals. This work

is licensed under the

Creative Commons

Attribution License.
Persistent hyperplastic primary vitreous (PHPV) is a congenital lesion due to incomplete regression of the embryonic ocular blood supply (hyaloid vasculature). ${ }^{1}$ It represents $28 \%$ of childhood presentations of leukocoria and is almost always accompanied by poor vision, micropthalmia and often retinal detachment. ${ }^{1,2,3}$ The absence of ocular calcifications helps distinguish PHPV from the more common retinoblastoma. ${ }^{4}$ The appearance of PHPV has been likened to that of a martini glass. The martini glass is represented by triangular retrolental fibrovascular tissue and a central tissue stalk of hyaloid remnant extending to the optic disc in Cloquet's canal (see Figure 1a). ${ }^{5}$ The retrolental fibrovascular tissue and stalk-like hyaloid remnant are hypointense to isointense on T1- and T2-weighted images and show enhancement post contrast administration. The globe may be hyperintense on T1-weighted images; this may represent either subhyaloid or subretinal fluid with blood degradation products (methaemoglobin) or high protein content (see Figure 1b). ${ }^{1}$

\section{Acknowledgements Competing interests}

The author declares that he has no financial or personal relationship(s) that may have inappropriately influenced him in writing this article.

\section{References}

1. Smirniotopoulos JG, Bargallo N, Mafee MF. Differential diagnosis of leukokoria: Radiologic-pathologic correlation. Radiographics. 1994;14(5):1059-1079. PMID: 7991814. http://dx.doi.org/10.1148/radiographics.14.5.7991814

2. Küker W, Ramaekers V. Persistent hyperplastic primary vitreous: MRI. Neuroradiology. 1999;41(7):520-522. PMID: 10450848. http:// dx.doi.org/10.1007/s002340050796

3. Sun MH, Kao LY, Kuo YH. Persistent hyperplastic primary vitreous: Magnetic resonance imaging and clinical findings. Chang Gung Med J. 2003 Apr;26(4):269-276. PMID: 12846526.

4. Edward DP, Mafee MF, Garcia-Valenzuela E, Weiss RA. Coats' disease and persistent hyperplastic primary vitreous. Role of MR imaging and CT. Radiol Clin North Am. 1998;36(6):1119-1131, x. PMID: 9884692.

5. Kaste SC, Jenkins JJ, Meyer D, Fontanesi J, Pratt CB. Persistent hyperplastic primary vitreous of the eye: Imaging findings with pathologic correlation. Am J Roentgenol. 1994;162(2):437-440. PMID: 8310942. http://dx.doi.org/10.2214/ajr.162.2.8310942

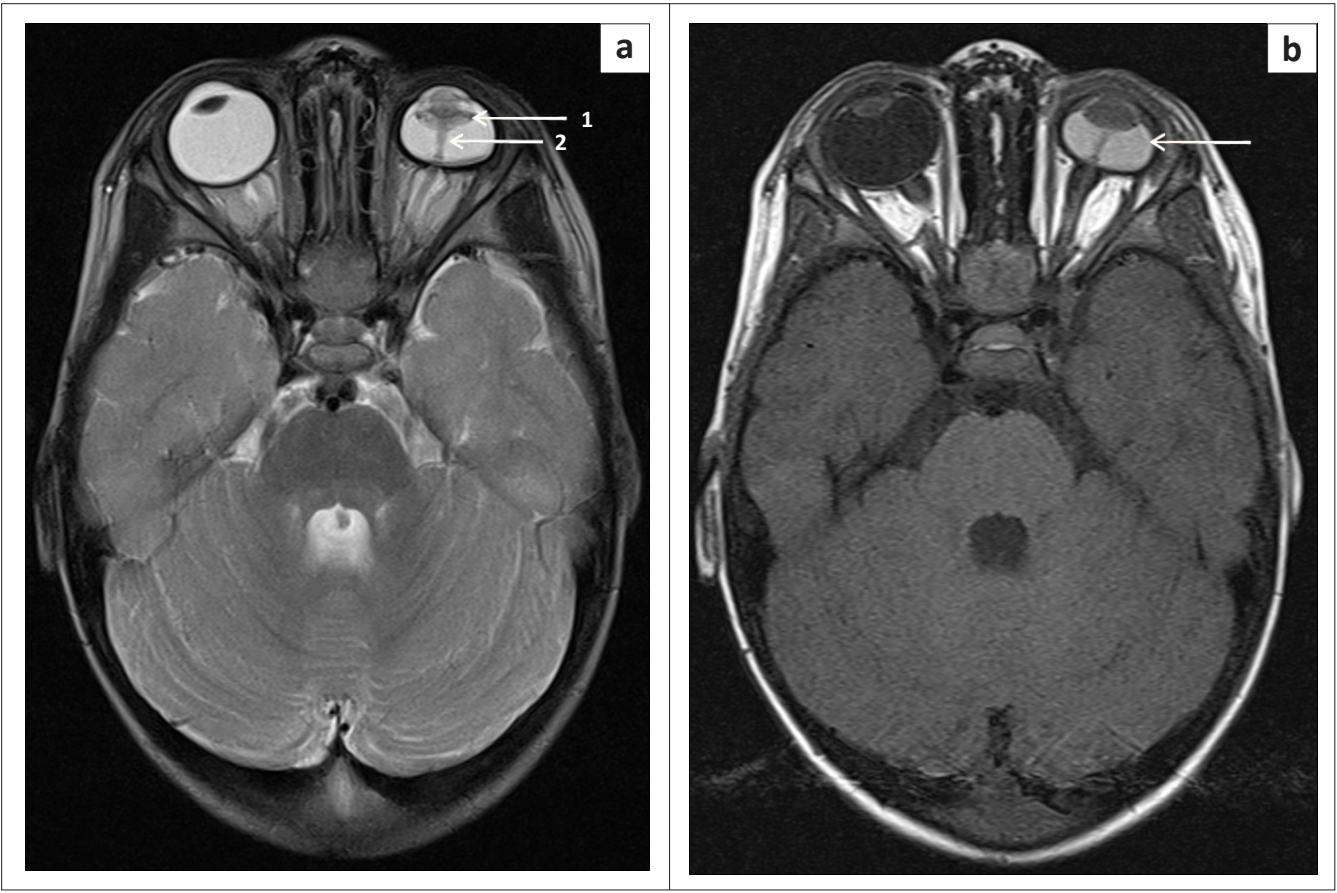

FIGURE 1: Axial T2-weighted (a) and axial T1-weighted (b) images show the triangular retrolental fibrovascular tissue (arrow 1) and a central tissue stalk of hyaloid remnant in Cloquet's canal (arrow 2) representing the 'martini glass' sign; (b) Micropthalmia and hyperintense vitreous (arrow) on T1-weighted image due to accumulation of blood degradation products or high protein content compared to normal right globe. 